\title{
Changes in the ENSO/SPCZ relationship from past to future climates
}

\author{
Marion Saint-Lu ${ }^{\mathrm{a}, *}$, Pascale Braconnot ${ }^{\mathrm{a}}$, Julie Leloup ${ }^{\mathrm{a}, \mathrm{b}}$, Matthieu \\ Lengaigne $^{\mathrm{b}}$, Olivier Marti ${ }^{\mathrm{a}}$ \\ ${ }^{a}$ Laboratoire des Sciences du Climat et de l'Environnement (LSCE), \\ UVSQ/CEA/CNRS, Orme des Merisiers, 91191 Gif-sur-Yvette, France \\ ${ }^{b}$ Laboratoire d'Océanographie et du Climat: Expérimentation et Approches Numériques \\ (LOCEAN), IRD/UPMC/CNRS/MNHN, \& place Jussieu, 75252 Paris Cedex 05, France
}

\begin{abstract}
The South Pacific Convergence Zone (SPCZ) is the main climate feature of the Southwest Pacific. It is characterized by a band of intense convective rainfall extending from the western Pacific warm pool to French Polynesia. Strong precipitation gradients within the SPCZ make local hydrologic conditions very sensitive to small displacements of this rainfall band, as those caused by El Niño and La Niña events. The associated rainfall fluctuations strongly impact the vulnerable Southwest Pacific countries. They are recorded in environmental indicators such as corals, used as proxies of past evolution of the El Niño/Southern Oscillation (ENSO). Here we analyze a set of paleoclimate and future climate simulations and present evidence that changes in the background tropical state largely control the mean SPCZ location. In contrast, changes in the background tropical state do not di-
\end{abstract}

\footnotetext{
*Corresponding author

Email addresses: marion.saint-lu@lsce.ipsl.fr (Marion Saint-Lu), pascale.braconnot@lsce.ipsl.fr (Pascale Braconnot), jllod@locean-ipsl.upmc.fr (Julie Leloup), lengaign@locean-ipsl.upmc.fr (Matthieu Lengaigne), olivier.marti@lsce.ipsl.fr (Olivier Marti) 
rectly control the interannual variability of the SPCZ location. We show that changes in the interannual variability of the SPCZ location cannot be directly imputable to changes in the ENSO amplitude, or rather the relationship between ENSO and the SPCZ location varies from one climate to another. We thus demonstrate that the teleconnection mechanisms inferred from the modern climate cannot be directly extrapolated to other climates. This study therefore calls for a cautious interpretation of climate reconstructions from environmental indicators in the Southwest Pacific with regard to ENSO variations.

Keywords:

SPCZ, ENSO, variability, interannual, teleconnection, paleoclimates

1 1. Introduction

2 The South Pacific Convergence Zone (SPCZ) is a band of low level con3 vergence and convective precipitation extending from Papua New Guinea 4 south-eastward towards French Polynesia (Vincent, 1994). It is fully devel5 oped during the austral summer from November to March (NDJFM).

6 The western portion of the SPCZ, considered as a "true tropical con7 vergence zone" by Kiladis et al. (1989), extends zonally over the western 8 Pacific warm pool. Its location is governed by underlying Sea Surface Temperature (SST) distribution and monsoon systems, especially the Australian monsoon (Kiladis et al., 1989). The eastern portion of the SPCZ has a southeastward diagonal orientation. Takahashi and Battisti (2007) suggest that this diagonal orientation originates from the streamlines orientation of the southeasterly trade winds in the so-called dry zone of the southeastern Pa- 
cific. They also state that the spatial geometry of this dry zone comes from the mechanical interaction between the westerly flow of the subtropical jet and the Andes. Since then, other studies have highlighted the role of largescale SST gradients on the existence and orientation of the SPCZ (Vincent, 1994; Widlansky et al., 2011, 2013).

At the interannual time scale, the SPCZ location is modulated by the El Niño/Southern Oscillation (ENSO). ENSO results from ocean-atmosphere coupling in the tropics (Philander, 1989). It influences tropical Pacific SST and winds, and thereby acts to displace the SPCZ. In particular El Niño and La Niña events respectively lead to northward and southward shifts of the SPCZ (Folland et al., 2002; Trenberth, 1976). This leads to severe droughts and floods (Kumar et al., 2006), a displacement of the tropical cyclone prone region, and an increase in coral bleaching and human diseases in the Southwest Pacific (Vincent et al., 2011; Glynn, 1984).

Environmental paleo-indicators such as fossil corals or giant clams record the past interannual rainfall variability and are the main high resolution paleo-datasets in the tropical Pacific (Corrège et al., 2000; McGregor and Gagan, 2004; Tudhope et al., 2001; Duprey et al., 2012; Cobb et al., 2013; Lazareth et al., 2013; Elliot et al., 2013). On the western side of the Pacific basin, most of them are located within the SPCZ area (see Fig.1). The present-day relationship between the amplitude of ENSO and the one of the SPCZ variability found from observations have led scientists to consider the amplitude of signals derived from these high resolution records as a proxy of ENSO amplitude in the past (Corrège et al., 2000; McGregor and Gagan, 2004; Tudhope et al., 2001; Elliot et al., 2013). However, a recent study 
suggests that the SPCZ shifts will be frequently more extreme in the future, despite no apparent consensus of changes in ENSO amplitude (Cai et al., 2012). This result raises the question whether changes in the SPCZ variability derived from past coral records can be directly interpreted as changes in ENSO amplitude in different paleo-climates. It calls for a better understanding of the sensitivity of the ENSO-SPCZ relationship to the background climate state.

In the present study, we consider four radically different climates simulated by seven Coupled General Circulation Models (CGCMs) from the Coupled Model Intercomparison Project phase 5 (CMIP5) (Taylor et al., 2012). Here, the control runs are the unperturbed pre-industrial simulations (PI) with greenhouse gas concentrations, aerosols and land use fixed to 1860 conditions. We then consider the case of a warmer future climate in response to $\mathrm{CO}_{2}$ forcing by using idealized simulations forced with four times the preindustrial levels of $\mathrm{CO}_{2}$ (4xCO2 hereafter). The two other experiments come from the Paleoclimate Modeling Intercomparison Project phase 3 (PMIP3) (Braconnot et al., 2012b). The Last Glacial Maximum experiment (LGM, 21 ky BP) simulates the cold and dry climate in response to extended ice sheet and lower $\mathrm{CO}_{2}$ that prevailed $21 \mathrm{ky}$ ago. The Mid-Holocene experiment (MH, 6 ky BP) simulates the change in the seasonal phase and amplitude prevailing 6 ky ago. It is induced by a change in the Earth's precession combined with increased obliquity that reduces insolation in the Tropics and enhances the inter-hemispheric insolation contrast during austral summer. Depending on the model and climate period considered, simulation lengths range from 100 to 1000 years. They are provided in Table 1 for the seven CGCMs 
(IPSL-CM5A, CNRM-CM5, FGOALS-g2, MIROC-ESM, MPI-ESM-P, MRICGCM3, CCSM4) for which ouputs for the 4 periods considered are available in the international database.

\section{Analyses of pre-industrial, paleo and future climates}

We first discuss the background climate state's control of the mean location of the SPCZ. The SPCZ simulated for the PI climate by the seven CGCMs exhibit a meridional tilt as observed (Fig.1). The tilt is typically underestimated compared to observations. In addition, CGCMs generally exhibit equatorial cold SST associated with the equatorial upwelling that extends too far west along the equator. These biases are common to most CGCMs (Brown et al., 2012) and might affect the interpretation of the results as discussed later.

The eastern portion of the SPCZ has been shown to be more influenced by the Pacific SST gradients and atmospheric circulation than the western portion (Vincent, 1994; Kiladis et al., 1989; Takahashi and Battisti, 2007; Widlansky et al., 2011, 2013). As we are interested in the large-scale features of the SPCZ-ENSO teleconnection, we focus our discussion below on the eastern portion of the SPCZ. Following Vincent et al. (2011), the SPCZ position is characterized by the location of the maximum NDJFM SPCZ precipitation over $170^{\circ} \mathrm{W}-150^{\circ} \mathrm{W}$ (refer to latE index hereafter).

The Southwest Pacific mean state is characterized in this study by the meridional SST gradient between the north of the SPCZ $\left(5^{\circ} \mathrm{S}-10^{\circ} \mathrm{S}\right)$ and the

\footnotetext{
${ }^{1}$ For the other trace gases and boundary conditions see Braconnot et al. (2012b)
} 
Table 1: Main forcings applied in each experiment, and number of years used in each experiment and model. For the $4 \mathrm{xCO} 2$ experiment, we remove the initial stabilization part of the simulation for each model, based on the NIÑO3 SST time series (the NIÑO3 index is defined as the average SST over $\left.150^{\circ} \mathrm{W}-90^{\circ} \mathrm{W}, 5^{\circ} \mathrm{N}-5^{\circ} \mathrm{S}\right)$.

\begin{tabular}{|c|c|c|c|c|}
\hline Simulation & Pre-industrial & MH (6 ky) & LGM & $4 \mathrm{xCO} 2$ \\
\hline Main forcings ${ }^{1}$ & $\mathrm{CO}_{2}: 280 \mathrm{ppm}$ & $\begin{array}{l}6 \text { ky } \\
\text { astronomical } \\
\text { parameters } \\
\text { (Berger, 1978) }\end{array}$ & $\begin{array}{l}\mathrm{CO}_{2}: 180 \mathrm{ppm}, \\
\text { and northern } \\
\text { ice sheet }\end{array}$ & $\begin{array}{l}\mathrm{CO}_{2}: \\
280 \times 4=1120 \mathrm{ppm}\end{array}$ \\
\hline \multicolumn{5}{|l|}{$\begin{array}{l}\text { Length of } \\
\text { simulation } \\
\text { (years) }\end{array}$} \\
\hline \\
\hline IPSL-CM5A & 1000 & 500 & 200 & 300 \\
\hline CCSM4 & 1051 & 301 & 101 & 126 \\
\hline CNRM-CM5 & 850 & 200 & 200 & 135 \\
\hline FGOALS-g2 & 900 & 685 & 100 & 193 \\
\hline MIROC-ESM & 630 & 100 & 100 & 125 \\
\hline MPI-ESM-P & 1156 & 100 & 100 & 125 \\
\hline MRI-CGCM3 & 500 & 100 & 100 & 130 \\
\hline
\end{tabular}




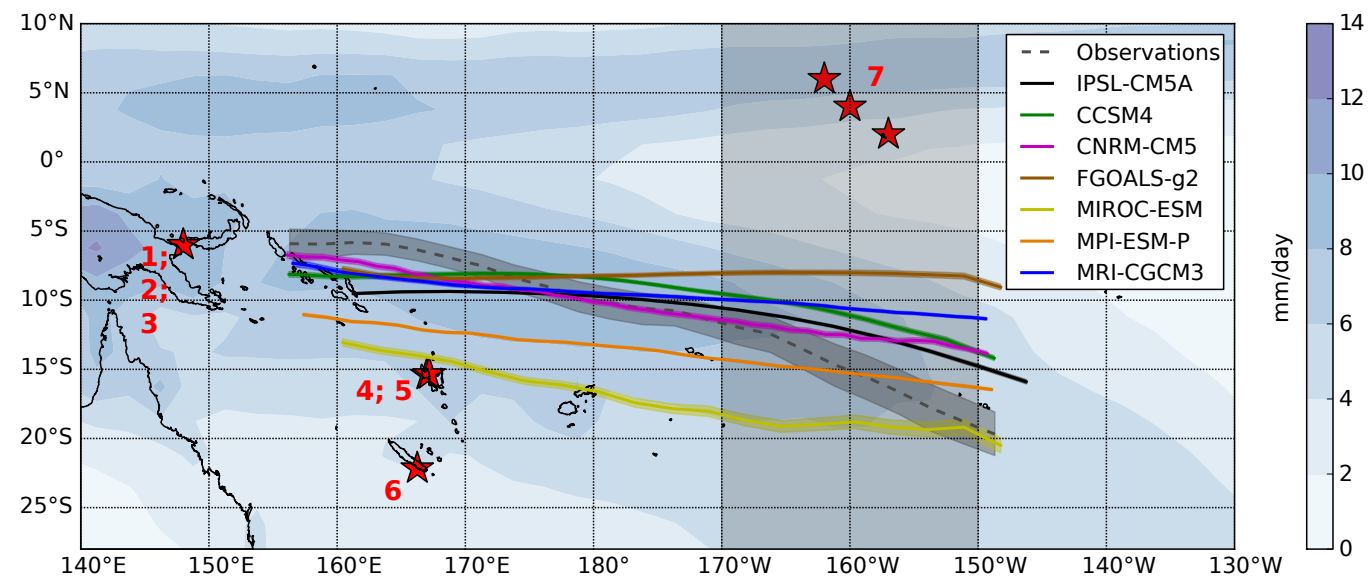

Figure 1: The SPCZ in the seven models and observations. Color shading shows the November to March (NDJFM) average precipitation as observed from 32 years of satellite dataset (Adler et al., 2003). Lines indicate the mean NDJFM SPCZ positions for the PI experiment of each CGCM and for observations, and colored shaded bands around indicate $90 \%$ confidence interval on the SPCZ position, computed with bootstrap resampling (see methods). Grey shaded vertical band defines the eastern portion of the SPCZ $\left(170^{\circ} \mathrm{W}-150^{\circ} \mathrm{W}\right)$. Red stars indicate locations of corals and giant clams and the red numbers link them to the corresponding references: 1-McGregor and Gagan (2004); 2-Tudhope et al. (2001); 3-Elliot et al. (2013); 4-Corrège et al. (2000); 5-Duprey et al. (2012); 6-Lazareth et al. (2013); 7-Cobb et al. (2013).

equatorial region $\left(0^{\circ}-5^{\circ} \mathrm{S}\right)$ averaged between $155^{\circ} \mathrm{E}$ and $120^{\circ} \mathrm{W}$. In the observations (Rayner, 2003; Adler et al., 2003), this gradient is about $0.8^{\circ} \mathrm{C}$ on average and corresponds to a latE index around $15^{\circ} \mathrm{S}$ (Fig.2a). It has been shown to be strongly related to the location of the SPCZ in present and future climates, as it is a key indicator of the wind and related humidity convergence from the equator to the SPCZ (Cai et al., 2012). Fig.2a shows that the mean meridional SST gradient is significantly anticorrelated with the mean latE index across all periods and models. The SPCZ thus tends to 
be shifted northward (southward) when the meridional SST gradient weakens (strengthens). This is what is usually observed during El Niño events: in response to equatorial warming - and more generally to a reduction of the SST gradient between the equator and the off-equatorial band - wind divergence above the equator decreases, slightly shifting northward the maximum moisture convergence and subsequently the SPCZ (Vincent et al., 2011). The same mechanism applies for an increase of the SST gradient as during a La Niña event. Note that Fig.2a also highlights that CGCMs underestimate the SPCZ tilt despite their tendency to simulate a larger than observed SST gradient in the PI simulations.

Our results show that the relationship between SST gradient and SPCZ position typically holds when considering individual CGCM changes from one climate to another (Fig.2b, c). In particular all the 4xCO2 simulations exhibit a reduced meridional SST gradient compared to PI (Fig.2b). This is due to the enhanced warming of the equator, as shown in previous studies for future climate projections (Xie et al., 2010; Liu et al., 2005). A corresponding northward shift of the SPCZ is simulated for 6 models out of 7 (Fig.2c), as the moisture convergence is shifted towards the equator. Results from the $\mathrm{MH}$ experiment mirror those from the $4 \mathrm{xCO} 2$ simulations, with an increased meridional SST gradient in 6 models out of 7 in response to the reduced austral summer insolation forcing in the tropics and the differential hemispheric insolation during the MH (Fig.2b). The strengthened SST gradient is associated with a southward shift of the SPCZ for the corresponding models (Fig.2c), and is in agreement with Mantsis et al. (2013) who also discuss this shift as a direct consequence of SST changes on both sides of 


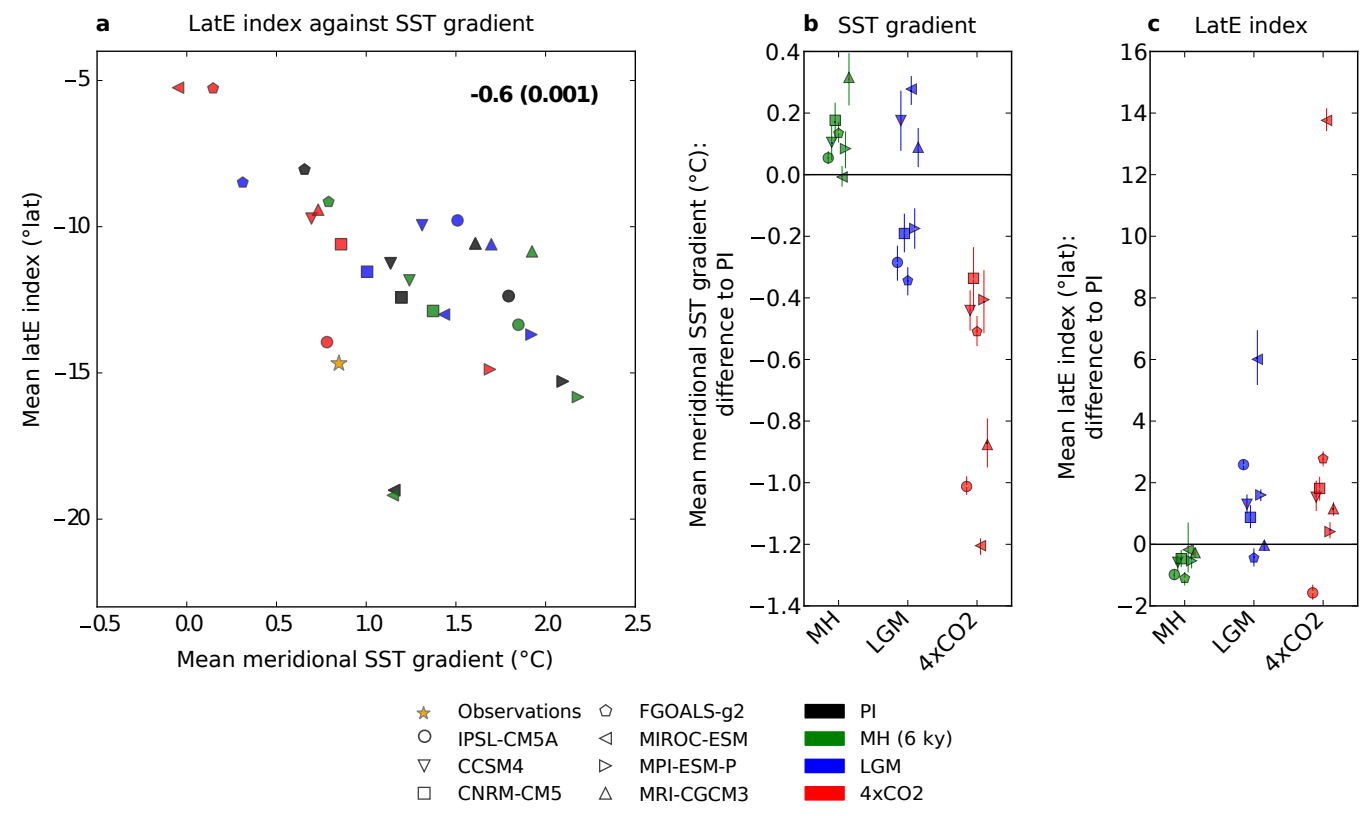

Figure 2: Changes in the mean eastern SPCZ position and the mean meridional SST gradient in austral summer for all models. (a) Relationship between the mean NDJFM latE index and the mean NDJFM meridional SST gradient in the model ensemble: values for all simulations and for observations. Numbers in the upper right corner indicate the Pearson correlation coefficient computed by excluding observations and its p-value in parenthesis. (b) Values for the mean NDJFM meridional SST gradient difference to PI for each simulation, in the model ensemble. (c) Same as $\mathbf{b}$ for the mean NDJFM latE index. Error bars indicate the $90 \%$ confidence interval, computed with bootstrap resampling (see methods). 
the SPCZ. Additionally, they highlight the role of other contributors: (i) insolation changes in the mid-Holocene damp the Australian monsoon affecting the western portion of the SPCZ, (ii) deformations of the westerly flow along the southwestern edge of the SPCZ causes enhanced precipitation in that region due to wave accumulation - see the "graveyard" theory (Widlansky et al., 2011; Trenberth, 1976). The relationship between the SST background change and the SPCZ location is however not as clear for the LGM. For this climate, 5 models out of 7 simulate a northward shift of the SPCZ compared to PI (Fig.2c), but there is no consensus on the sign of the change in the meridional SST gradient (Fig.2b). This result echoes the lack of consensus between model results regarding the LGM Indo-Pacific mean state (DiNezio et al., 2011).

\section{Change in the SPCZ variability}

Following the analysis of the climatological SPCZ changes in the previous section, we focus here on the response of the SPCZ variability to ENSO forcing in the different climates (Fig.3). The variability of the SPCZ and ENSO are inferred from the standard deviations (SD) of the NDJFM averaged latE and NIÑO3 index (SST average over $150^{\circ} \mathrm{W}-90^{\circ} \mathrm{W}, 5^{\circ} \mathrm{N}-5^{\circ} \mathrm{S}$ ) respectively. The latE SD is increased in 4 models out of 7 in 4xCO2 (one model gives no change) and reduced in 6 models out of 7 in the LGM (Fig.3b). However, models do not correspondingly agree on the changes in ENSO for these two experiments as illustrated by the NINOO3 SD change (Fig.3c). It is worth pointing out the absence of symmetry in the ENSO change between these two climates, whereas they correspond to opposite signs of $\mathrm{CO}_{2}$ forcing. In- 
deed, 5 models simulate the same tendency of ENSO change in response to both the $4 \mathrm{xCO} 2$ and the LGM forcings. Consequently, the change in the SPCZ variability in these two climates seems to be independent from the change in ENSO.

The stronger latE SD found in the $4 \mathrm{xCO} 2$ simulations are in line with the results of Cai et al. (2012) who predict an increase in the frequency of extreme northward SPCZ shifts in the future, in response to the reduced meridional SST gradient associated with global warming. The climatological weakening of the meridional SST gradient indeed makes it easier for this meridional SST gradient to vanish, a key feature associated with the occurrence of extreme swings of the SPCZ. Our results are consistent with their statement, as most of the $4 \mathrm{xCO} 2$ simulations exhibit both a stronger latE SD and a weaker climatological SST gradient (Fig.3b and Fig.2b).

This relationship however does not hold for the past climates, as shown by the lack of correlation between changes in the latE SD and the mean meridional SST gradient (Supplementary Fig.A.5). In the radically different LGM climate, the damped SPCZ variability found in 6 models out of 7 cannot be explained by the mean SST distribution as CGCMs disagree. It is worth noting that water vapor and convective activity within the SPCZ region are impacted by the strong cooling that characterizes the LGM period (not shown), and that this may also affect the SPCZ variability.

A similar lack of relationship is found for the MH: 6 models out of 7 agree on a reduction of the NIÑO3 SD - 4 of them significantly - (Fig.3c), in line with the MH ENSO reduction described in other model studies (Braconnot et al., 2012a; Luan et al., 2012; Clement et al., 2000; Zheng et al., 2008). 

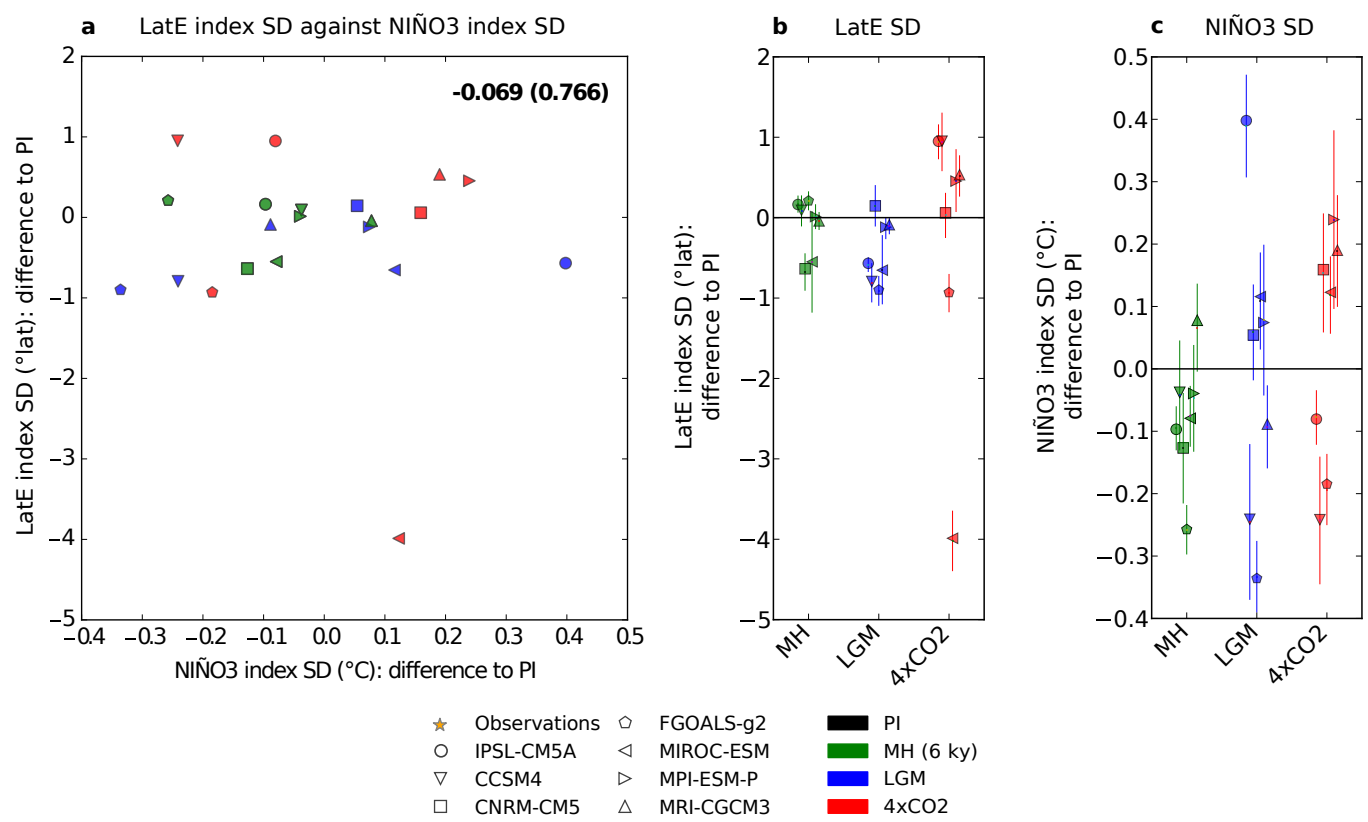

Figure 3: Changes in the SPCZ position variability and the SST summer variability in the eastern equatorial Pacific for all models. (a) Relationship between the NDJFM latE index standard deviation (SD) and the NDJFM NIÑO3 index SD in the model ensemble: values for the difference to pre-industrial simulation (PI) for each other simulation of the same model. Numbers in the upper right corner indicate the corresponding Pearson correlation coefficient and its p-value in parenthesis. (b) Values for the NDJFM latE index SD difference to PI for each simulation, in the model ensemble. (c) Same as $\mathbf{b}$ for the NDJFM NIÑO3 index SD. Error bars indicate the $90 \%$ confidence interval, computed with bootstrap resampling (see methods). 
Despite the agreement on both ENSO reduction and meridional SST gradient enhancement (Fig.2b), there is no model consensus about the MH SPCZ variability (Fig.3b). The above results show that changes in ENSO amplitude cannot be directly related to changes in SPCZ variability in different climates, as confirmed by the lack of correlation between the latE SD and NINOO3 SD index (Fig.3a).

A more in-depth investigation of the relationship between ENSO and the SPCZ variability for different climates is further provided with the IPSLCM5A model (low resolution version IPSL-CM5A-LR) (Marti et al., 2010; Dufresne et al., 2013). Instead of only considering changes in the NIÑO3 SD against the latE SD, the long and stable simulations available for this model (Dufresne et al., 2013; Kageyama et al., 2013) allow us to directly analyze the relationship between El Niño/La Niña events and identified SPCZ northward/southward shifts. IPSL-CM5A is indeed the only model for which all simulation lengths provided in the database equal or exceed 200 years, allowing us to select enough El Niño/La Niña events to build robust composites. In addition, we run a late mid-Holocene (4 ky BP, $4 \mathrm{~K}$ in the following) simulation with this model to further assess the role of the insolation forcing. For each IPSL-CM5A experiment, El Niño, La Niña and normal years are identified using a common NIÑO3 SST anomaly threshold (Braconnot et al., 2012a; Luan et al., 2012) (see methods). We use a similar SPCZ shift threshold on the latE index to classify years where the SPCZ location is northward shifted, southward shifted and neutral. Results are shown in Fig.4. Although we focus here on IPSL-CM5A, we also classified years as El Niño/La Niña and northward/southward SPCZ shifts in the simulations of other CGCMs; 

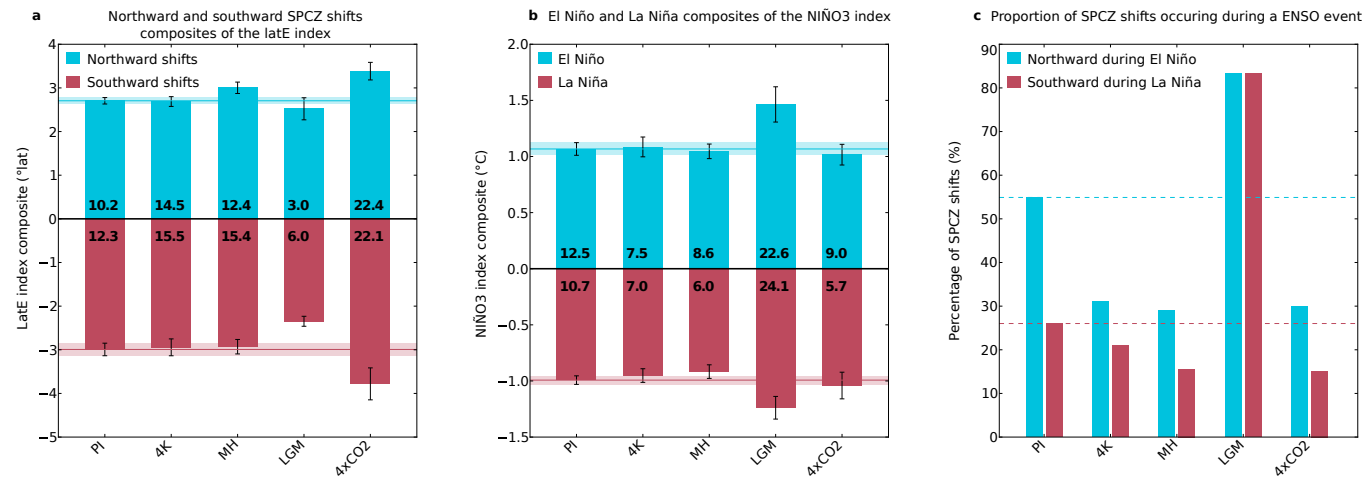

Figure 4: Changes in frequency and amplitude of SPCZ shifts and ENSO events, and matches between both types of events, with IPSL-CM5A. (a) Composite values of the NDJFM latE index over selected years of north and south SPCZ shifts, i.e. mean values over these selected years. Error bars indicate the $95 \%$ confidence interval, assuming a normal distribution. Blue and red horizontal lines and shaded bands around indicate the PI latE composite and its confidence interval. Numbers indicate the percentage of selected years regarding the length of each simulation. (b) Same as a for the composite values of the NDJFM NIÑO3 index over El Niño and La Niña years. (c) Percentage of north (south) SPCZ shifts going with El Niño (La Niña) events, regarding total number of north (south) shifts. Horizontal lines indicate PI values.

results are detailed in supplementary Fig. B.6 and Fig. C.7.

Fig.4a shows that in $4 \mathrm{xCO} 2$ and $\mathrm{MH}$ experiments, there are more $\mathrm{SPCZ}$ shifts per century and of larger amplitude than in PI. These changes are especially pronounced in $4 \mathrm{xCO} 2$ with a doubling of the occurrence of northward/southward SPCZ shifts per century. Their amplitude is also significantly larger (about 0.5 up to $1^{\circ}$ lat at $5 \%$ level). The $4 \mathrm{~K}$ simulation likewise gives an increase in frequency but no significant change in amplitude. This enhanced SPCZ variability is not consistent with ENSO changes as, in these three climates $(4 \mathrm{xCO} 2, \mathrm{MH}$ and $4 \mathrm{~K})$, the occurrence of El Niño and La Niña 
events decreases compared to PI (Fig.4b). As a consequence, in these three climates there are fewer cases where northward (southward) SPCZ shifts are associated to El Niño (La Niña) events (Fig.4c). In contrast, the IPSLCM5A LGM experiment exhibits an opposite situation: SPCZ northward (resp. southward) shifts are reduced by $70 \%$ (resp. 50\%), while the number of El Niño/La Niña events nearly doubles and their amplitude significantly increases. As a result, the SPCZ movements in this climate are largely driven by ENSO events (Fig.4c).

\section{Conclusions}

One of the main conclusions emerging from this multi-model analysis is that changes in the SPCZ variability cannot be directly inferred from changes in ENSO. Our analyses show that changes in both ENSO and SPCZ do not covary between climates and models. They are associated with differences in the mean spatial structures of the Southwest Pacific, as shown by shifts in the mean SPCZ location together with the meridional SST gradient changes. These differences in the mean state may affect the SPCZ variability independently from ENSO. Also emerging from this multi-model analysis, in the $4 \mathrm{xCO} 2$ experiment the reduction of the mean meridional SST gradient displaces the mean SPCZ northward leading to an increase frequency of shifts. In the LGM, the SPCZ exhibits a mean northward displacement and its spatial variability is damped. In the $\mathrm{MH}$ and $4 \mathrm{~K}$, the increased meridional SST gradient displaces the mean SPCZ southward and ENSO is reduced, but these changes may have concurrent effects on the SPCZ spatial variability, explaining the lack of consensus between models on this point. The change 
in the SPCZ variability is therefore not primarily determined by ENSO.

Our results also stress that the SPCZ response to ENSO influence is likely to depend on the climate, suggesting that ENSO signature in the Southwest Pacific is mean-state dependent. All these modifications may impact the sign and amplitude of El Niño anomalies as recorded in paleo-indicators. Our results suggest that the El Niño signature on rainfall at a given site was not necessarily of the same sign or of similar amplitude in past climates than nowadays. The biased SPCZ location simulated by the CGCMs does not however allow us to confidently assess the sign and amplitude of El Niño rainfall anomaly in the past climates at the scale of the Southwest Pacific islands. In addition, CGCMs biases in the Southwest Pacific region may contribute to some extent to the lack of agreement on the changes in the SPCZ-ENSO teleconnection in response to different climate forcings. However, these caveats are unlikely to affect the main result of the present study, i.e. the fact that the relationship between ENSO and the SPCZ location strongly varies from one climate to another, as this result is consistent across all models.

This work then calls for careful interpretation of paleo-data outside the equatorial Pacific region and for the development of innovative strategies for model-data comparisons in order to understand the SPCZ variability and its relationship with ENSO.

\section{Methods}

SPCZ position and latE index. The location of the SPCZ is determined from the average of rainfall from November to March (NDJFM) at each model 
grid point. In the region between $150^{\circ} \mathrm{E}-150^{\circ} \mathrm{W}$ and $0^{\circ}-30^{\circ} \mathrm{S}$, the latitude of the SPCZ corresponds to the latitude of the NDJFM rainfall maximum for each longitude, where the NDJFM rainfall rate is over $6 \mathrm{~mm} /$ day. In the eastern longitudinal portion $150^{\circ} \mathrm{W}-142^{\circ} \mathrm{W}$, the NDJFM rainfall maximum is only taken within $11^{\circ} \mathrm{S}$ to $30^{\circ} \mathrm{S}$. In Fig. 1, the SPCZ line is smoothed over 5 longitude grid points. With this classification of the SPCZ, the latE index is then defined as the average SPCZ latitude over $170^{\circ} \mathrm{W}-150^{\circ} \mathrm{W}$. For each dataset, the mean or climatological SPCZ position is determined by averaging all positions computed for the individual years.

Meridional SST gradient. The meridional SST gradient is also computed from SST average from November to March (NDJFM SST). The meridional SST gradient is defined as the average NDJFM SST over the southwestern off-equatorial region $\left(10^{\circ} \mathrm{S}-5^{\circ} \mathrm{S}, 155^{\circ} \mathrm{E}-120^{\circ} \mathrm{W}\right)$ minus the average over the southwestern equatorial region $\left(5^{\circ} \mathrm{S}-0^{\circ}, 155^{\circ} \mathrm{E}-120^{\circ} \mathrm{W}\right)$.

Selection of El Niño, La Niña and normal years. In this study we classify the different years into El Niño, La Niña or normal years following Braconnot et al. (2012a). We consider the NIÑO3 index defined as the average NDJFM SST over the NIÑO3 box $\left(150^{\circ} \mathrm{W}-90^{\circ} \mathrm{W}, 5^{\circ} \mathrm{N}-5^{\circ} \mathrm{S}\right)$. For each dataset, a year is defined as an El Niño (La Niña) year when its NIÑO3 index anomaly is greater (lower) than the NIÑO3 SD of the PI experiment multiplied by 1.2 $(-1.2)$.

Selection of north, south and neutral SPCZ shifts. We use NDJFM latE index as defined above. A year is defined as a north (south) SPCZ shifted year when its latE index anomaly is greater (lower) than the latE SD of 
the PI experiment multiplied by $1.2(-1.2)$. This criterion is an analogue to the El Niño/La Niña selection criterion described above (Methods). We also considered clustering analyses (not shown), but it gave similar results and we decided to keep the simplest approach.

Bootstrap estimations. The 90\% confidence intervals in Fig. 1 are produced by bootstrap resampling: for each dataset, 10,000 estimations of the mean SPCZ position are produced by randomly sampling 10,000 samples in the original dataset of the same size ( 1 year $=1$ value). The $90 \%$ confidence interval consists of the range between the value to which $5 \%$ of estimations are inferior and the value to which $5 \%$ of estimations are superior. Concerning error bars in Fig. 2 and Fig. 3 (panels b and c): for each simulation of each CGCM, 100 estimations of the variable of interest (mean latE index, mean meridional SST gradient, latE SD or NIÑO3 SD) are produced by bootstrap resampling (100 samples of the same size than the original dataset are randomly sampled in the original dataset). We then obtain 10,000 estimations of the difference between the $\mathrm{MH} / \mathrm{LGM} / 4 \mathrm{xCO} 2$ and the PI for each CGCM, by subtracting successively the 100 estimations for the PI to each of the 100 estimations for the $\mathrm{MH} / \mathrm{LGM} / 4 \mathrm{xCO} 2$. The $90 \%$ confidence interval consists of the percentiles $5-95 \%$.

\section{Authors contributions}

M.S-L., P.B., J.L. and M.L. coordinated the study and wrote the paper. M.S.L., M.L. and J.L. developed and performed analyses. O.M. and P.B. performed paleoclimate simulations. The results and their interpretation 
were discussed by all authors and all authors contributed to refine the paper and approved the final article.

\section{Acknowledgments}

This work was supported by the French ANR Project ELPASO (no. 2010 BLANC 608 01), and by the Knowledge and Innovation Community ClimateKIC from the European Institute of Innovation and Technology (EIT). We acknowledge the World Climate Research Programme's Working Group on Coupled Modelling, which is responsible for CMIP, and we thank the climate modeling groups (listed in Table 1 of this paper) for producing and making available their model output. For CMIP the U.S. Department of Energy's Program for Climate Model Diagnosis and Intercomparison provides coordinating support and led development of software infrastructure in partnership with the Global Organization for Earth System Science Portals. This study benefited from the IPSL Prodiguer-Ciclad facility which is supported by CNRS, UPMC, Labex L-IPSL which is funded by the ANR (Grant \#ANR-10-LABX-0018) and by the European FP7 IS-ENES2 project (Grant \#312979). The authors would like to thank the NASA/Goddard Space Flight Center's Laboratory for Atmospheres for developing the GPCP combined precipitation data as a contribution to the GEWEX Global Precipitation Climatology Project, as well as the U.K. Met. Office for use of the HadISST dataset. We acknowledge the three anonymous reviewers and Simon Borlace for their useful comments, which led to improve the manuscript. 


\section{Appendix A. Relationship between the change in the SPCZ vari- ability and the change in the mean SST gradient}

Several complementary analyses were done to discuss the relationship between the change in the SPCZ variability and the change in the mean SST gradient. Panel a of Fig. A.5 shows that the change in the SPCZ variability is not correlated with the change in the mean meridional SST gradient, in this set of simulations. However, one particular simulation $(4 \mathrm{xCO} 2$ for MIROCESM) is an outlier which may degrade the correlation. By excluding it, we obtain a Pearson coefficient of $\mathbf{- 0 . 4 5 3}(\mathrm{p}$-value=0.045), showing a slight anti-correlation between latE SD change and mean SST gradient change. As discussed in the text, our results do not exhibit such a relationship between the reference period (PI) and the other climates, except for the $4 \mathrm{xCO} 2$ climate. This anti-correlation may result from an existing relationship across models rather than across periods. This is confirmed with the panel $\mathbf{b}$ showing the absolute values for all simulations of the model ensemble rather than the difference values to PI. Although no correlation appears, MIROC-ESM is again an outlier (at least concerning the PI, MH and LGM simulations). If we exclude this model when estimating the correlation, the Pearson coefficient value is $\mathbf{- 0 . 5 4 5}$ ( $\mathrm{p}$-value $=\mathbf{0 . 0 0 6})$, exhibiting an anti-correlation which is significant given the small p-value.

By excluding the outlier MIROC-ESM, it appears that the relationship between a reduced (strengthened) meridional SST gradient and an enhanced (damped) SPCZ variability exists from one model to another. This relationship is not systematically valid from one climate to another. This result shows that differences between models are larger than differences between 

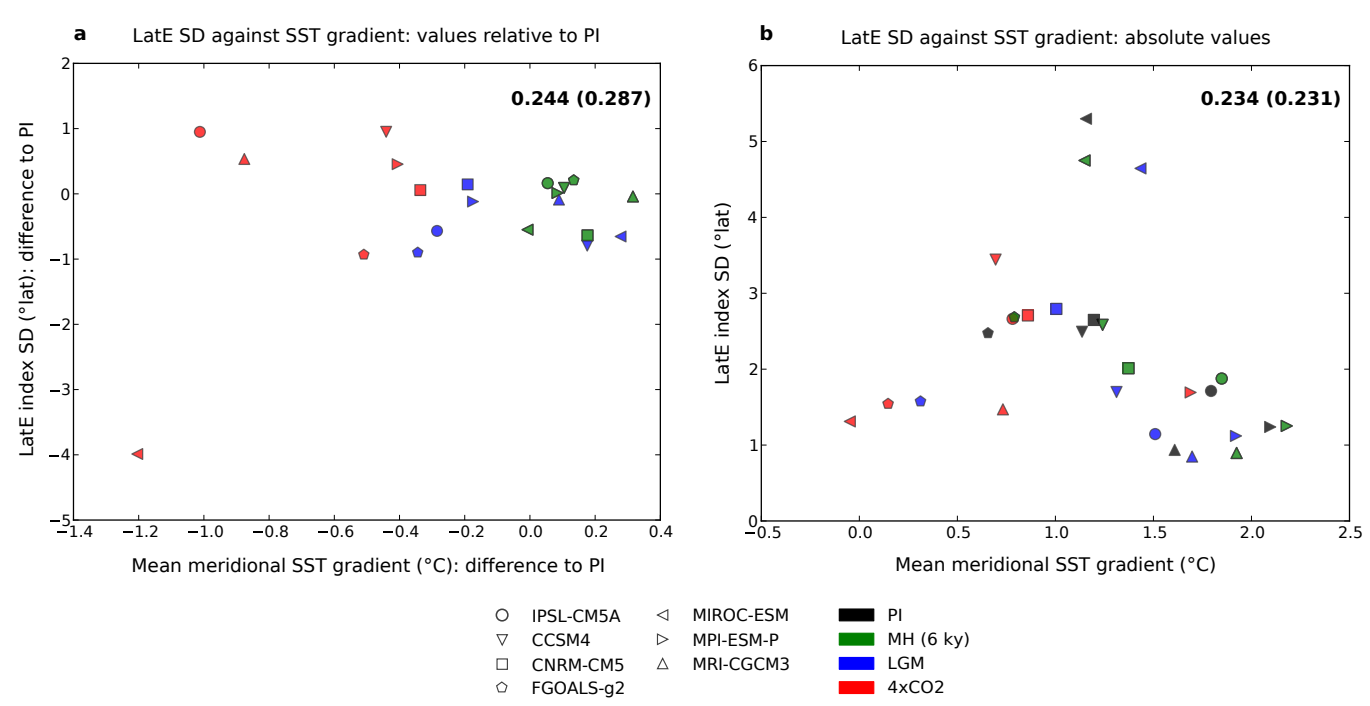

the different climates simulated by a particular model. Most importantly, it illustrates that applying an external forcing modifies the dominant mechanisms acting on the SPCZ variability. For example in the 4xCO2 simulation, the weakening of the meridional SST gradient acts to increase the SPCZ location variability, but the impact of the meridional SST gradient on the SPCZ variability for other climates may be minor compared to other larger changes.

Figure A.5: Relationship between the NDFJM latE index standard deviation (SD) and the mean NDJFM meridional SST gradient in the model ensemble: (a) Values for the difference to pre-industrial simulation (PI) for each other simulation of the same model. (b) Absolute values for all simulations. Numbers in the upper right corner indicate the Pearson correlation coefficient and its p-value in parenthesis. 


\section{Appendix B. Changes in frequency and amplitude of SPCZ shifts and ENSO events, and matches between both types of events, with CNRM-CM5 MPI-ESM-P and MRI- CGCM3}

Fig. B.6 is as Fig. 4 (showing IPSL-CM5A results) but for three other CGCMs CNRM-CM5, MPI-ESM-P and MRI-CGCM3. Results for the remaining CGCMs considered in this study are not shown here because there are too few SPCZ shifts and/or ENSO events selected with our criteria (see methods) for some of their simulations - in most cases LGM and 4xCO2 - as shown by Fig. C.7. For the three CGCMs shown here some simulations are also very short, which questions the significance of their results and is the reason why we chose to focus on IPSL-CM5A in the main text.

For the three CGCMs presented here - as well as for IPSL-CM5A in the main text - the matching between SPCZ shifts and ENSO events is modified across the climates. This suggests that the teleconnection is different.

For example, MPI-ESM-P simulates a reduction of the SPCZ shifts frequency in the LGM as well as an amplification of ENSO, resulting in an increase of the number of SPCZ shifts matching with ENSO events. The contrary is found for the $\mathrm{MH}$ simulation of this model. It is worth pointing out that in some cases - like the MPI-ESM-P 4xCO2 and the MRI-CGCM3 LGM simulations - ENSO and the SPCZ variability are both increased or decreased compared to pre-industrial (PI) but the matching between both is still modified (although we cannot assure the significance of the results). Concerning CNRM-CM5, the teleconnection is also slightly modified across the different simulations. For this model there seems to be an asymmetry be- 
376 tween the selection of north and south SPCZ shifts, and between Niño/Niña 377 events, as they present in most cases an opposite change compared to PI. 

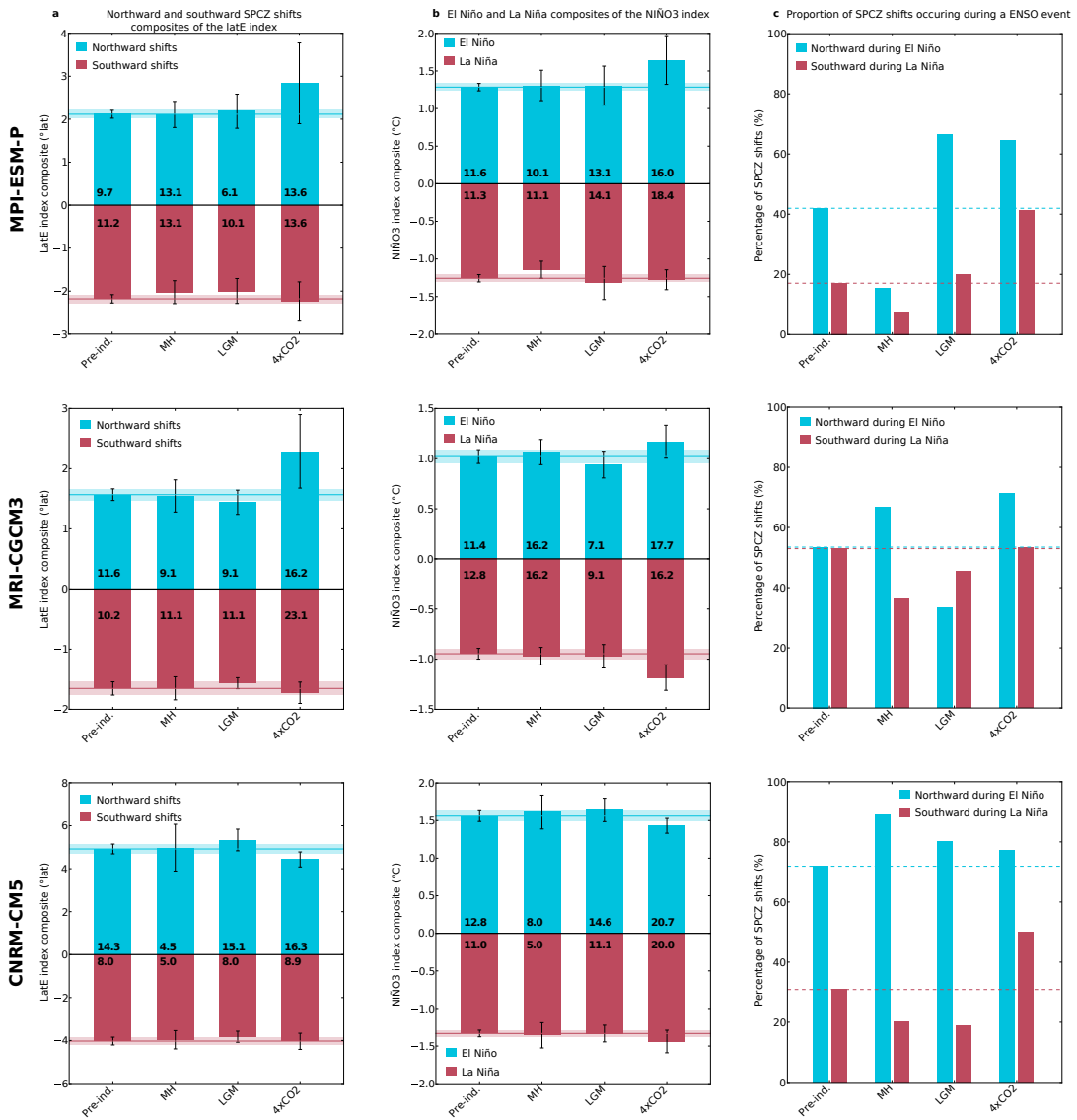

Figure B.6: (a) Composite values of the NDJFM latE index over selected years of north and south SPCZ shifts, i.e. mean values over these selected years. Error bars indicate the $95 \%$ confidence interval, assuming a normal distribution. Blue and red horizontal lines and shaded bands around indicate the PI latE composite and its confidence interval. Numbers indicate the percentage of selected years regarding the length of each simulation. (b) Same as a for the composite values of the NDJFM NIÑO3 index over El Niño and La Niña years. (c) Percentage of north (south) SPCZ shifts going with El Niño (La Niña) events, regarding total number of north (south) shifts. Horizontal lines indicate PI values. Top: CNRM-CM5; middle: MPI-ESM-P; bottom: MRI-CGCM3. 


\section{Appendix C. SPCZ shifts and Niño/Niña occurrences as simulated by the models compared to PI}

Fig. C.7 shows for the model ensemble the percentage of selected: a SPCZ north shifts, $\mathbf{b}$ SPCZ south shifts, $\mathbf{c}$ El Niño events, $\mathbf{d}$ La Niña events, regarding the length of each simulation and in difference to pre-industrial (PI).

From this figure, we note that there are few events selected (Niño/Niña or south/north SPCZ shifts) in each simulation of most models, because in most cases the simulations are too short (less than 200 years, see Table 1).

However, changes in the percentage of selected events (in $\mathbf{a}, \mathbf{b}, \mathbf{c}$ and $\mathbf{d}$ ) yields the same conclusions as changes in the latE and NIÑO3 index standard deviations (Fig.3). The only difference occurs in the LGM simulation: while 6 models out of 7 reduce the latE index standard deviation compared to PI, 6 models out of 7 produce less SPCZ north shifts than in PI but only 4 models also produce less SPCZ south shifts (one gives no change). 

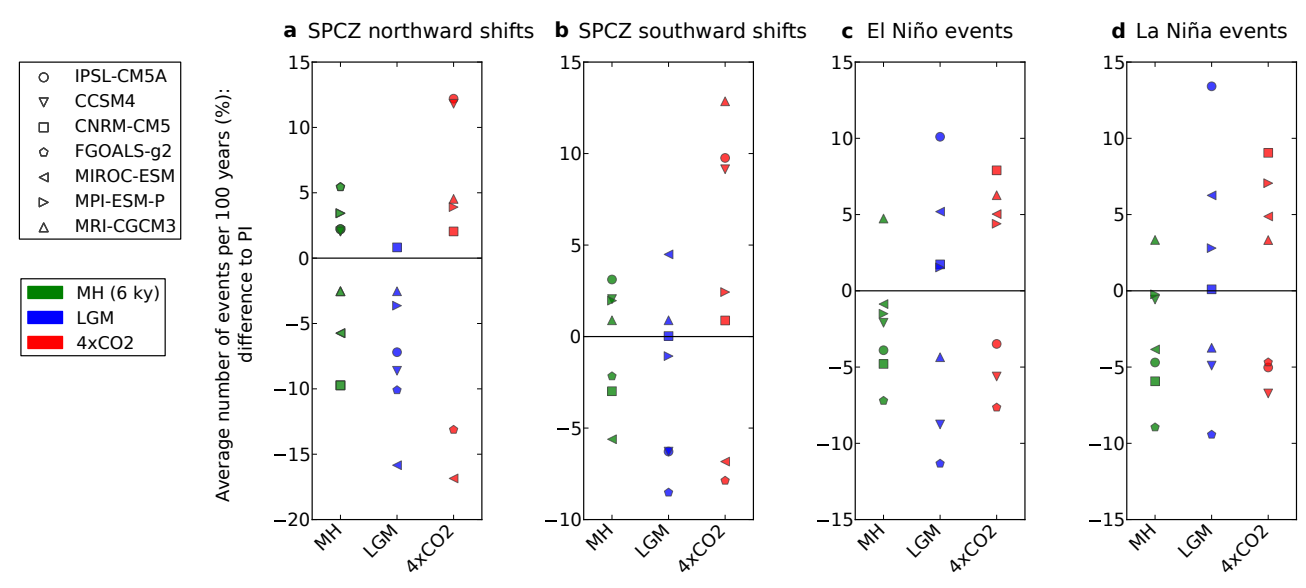

Figure C.7: Differences to PI for each simulation for all models of: (a) The percentage of north shifted SPCZ years (i.e. average number of selected years per century); (b) the percentage of south shifted SPCZ years; (c) the percentage of El Niño years; (d) the percentage of La Niña years. See methods for years selection. 


\section{References}

Adler RF, et al. (2003). The Version-2 Global Precipitation Climatology Project (GPCP) Monthly Precipitation Analysis (1979-Present). J. Hydrometeorol., 4(6):1147-1167. doi:10.1175/15257541(2003)004<1147:TVGPCP > 2.0.CO;2.

Berger A (1978). Long-Term Variations of Daily Insolation and Quaternary Climatic Changes. J. Atmos. Sci., 35(12):2362-2367. doi:10.1175/15200469(1978)035<2362:LTVODI >2.0.CO;2.

Braconnot P, Luan Y, Brewer S, and Zheng W (2012a). Impact of Earth's orbit and freshwater fluxes on Holocene climate mean seasonal cycle and ENSO characteristics. Clim. Dyn., 38(5-6):1081-1092. doi:10.1007/s00382011-1029-x.

Braconnot P, et al. (2012b). Evaluation of climate models using palaeoclimatic data. Nature Clim. Change, 2(6):417-424. doi: 10.1038/nclimate1456.

Brown JR, Moise AF, and Colman RA (2012). The South Pacific Convergence Zone in CMIP5 simulations of historical and future climate. Clim. Dyn., pages 1-19. doi:10.1007/s00382-012-1591-x.

Cai W, et al. (2012). More extreme swings of the South Pacific convergence zone due to greenhouse warming. Nature, 488(7411):365-369. doi: $10.1038 /$ nature11358. 
Clement AC, Seager R, and Cane MA (2000). Suppression of El Niño during the Mid-Holocene by changes in the Earth's orbit. Paleoceanography, 15(6):731-737. doi:10.1029/1999PA000466.

Cobb KM, et al. (2013). Highly Variable El Nino-Southern Oscillation Throughout the Holocene. Science, 339(6115):67-70. doi: 10.1126/science.1228246.

Corrège T, et al. (2000). Evidence for stronger El Niño-Southern Oscillation (ENSO) Events in a Mid-Holocene massive coral. Paleoceanography, 15(4):465-470. doi:10.1029/1999PA000409.

DiNezio PN, et al. (2011). The response of the Walker circulation to Last Glacial Maximum forcing: Implications for detection in proxies. Paleoceanography, 26(3). doi:10.1029/2010PA002083.

Dufresne JL, et al. (2013). Climate change projections using the IPSL-CM5 Earth System Model: from CMIP3 to CMIP5. Clim. Dyn., 40(9-10):21232165. doi:10.1007/s00382-012-1636-1.

Duprey N, et al. (2012). Early mid-Holocene SST variability and surfaceocean water balance in the southwest Pacific. Paleoceanography, 27(4). doi:10.1029/2012PA002350.

Elliot M, Welsh K, and Driscoll R (2013). Giant clam stable isotope profiles from Papua New Guinea faithfully record all the major El Niño events between 1986 and 2003, thus illustrating the usefulness of this archive to reconstruct past ENSO variability. PAGES news, 21(2):54-55. 
Folland CK, Renwick JA, Salinger MJ, and Mullan AB (2002). Relative influences of the Interdecadal Pacific Oscillation and ENSO on the South Pacific Convergence Zone. Geophys. Res. Lett., 29(13):21-1-21-4. doi: 10.1029/2001GL014201.

Glynn PW (1984). Widespread Coral Mortality and the 1982-83 El Niño Warming Event. Environ. Conserv., 11(02):133-146. doi: 10.1017/S0376892900013825.

Kageyama M, et al. (2013). Mid-Holocene and Last Glacial Maximum climate simulations with the IPSL model_part I: comparing IPSL_CM5A to IPSL_CM4. Clim. Dyn., 40(9-10):2447-2468. doi:10.1007/s00382-012$1488-8$.

Kiladis GN, von Storch H, and Loon H (1989). Origin of the South Pacific Convergence Zone. J. Clim., 2(10):1185-1195. doi:10.1175/15200442(1989)002<1185:OOTSPC > 2.0.CO;2.

Kumar VV, Deo RC, and Ramachandran V (2006). Total rain accumulation and rain-rate analysis for small tropical Pacific islands: a case study of Suva, Fiji. Atmos. Sci. Lett., 7(3):53-58. doi:10.1002/asl.131.

Lazareth CE, et al. (2013). Mid-Holocene climate in New Caledonia (southwest Pacific): coral and PMIP models monthly resolved results. Quaternary Sci. Rev., 69:83-97. doi:10.1016/j.quascirev.2013.02.024.

Liu Z, Vavrus S, He F, Wen N, and Zhong Y (2005). Rethinking Tropical Ocean Response to Global Warming: The Enhanced Equatorial Warming*. J. Clim., 18(22):4684-4700. doi:10.1175/JCLI3579.1. 
Luan Y, Braconnot P, Yu Y, Zheng W, and Marti O (2012). Early and midHolocene climate in the tropical Pacific: seasonal cycle and interannual variability induced by insolation changes. Clim. Past, 8(3):1093-1108. doi: $10.5194 / \mathrm{cp}-8-1093-2012$.

Mantsis DF, Lintner BR, Broccoli AJ, and Khodri M (2013). Mechanisms of Mid-Holocene Precipitation Change in the South Pacific Convergence Zone. J. Clim., 26(18):6937-6953. doi:10.1175/JCLI-D-12-00674.1. WOS:000324057600011.

Marti O, et al. (2010). Key features of the IPSL ocean atmosphere model and its sensitivity to atmospheric resolution. Clim. Dyn., 34(1):1-26. doi: $10.1007 / \mathrm{s} 00382-009-0640-6$.

McGregor HV and Gagan MK (2004). Western Pacific coral delta18O records of anomalous Holocene variability in the El Niño-Southern Oscillation. Geophys. Res. Lett., 31(11). doi:10.1029/2004GL019972.

Philander SG (1989). El Nino, La Nina, and the Southern Oscillation. Academic Press.

Rayner NA (2003). Global analyses of sea surface temperature, sea ice, and night marine air temperature since the late nineteenth century. J. Geophys. Res., 108(D14). doi:10.1029/2002JD002670.

Takahashi K and Battisti DS (2007). Processes Controlling the Mean Tropical Pacific Precipitation Pattern. Part II: The SPCZ and the Southeast Pacific Dry Zone. J. Clim., 20(23):5696-5706. doi:10.1175/2007JCLI1656.1. 
Taylor KE, Stouffer RJ, and Meehl GA (2012). An Overview of CMIP5 and the Experiment Design. Bull. Am. Meteorol. Soc., 93(4):485-498. doi: 10.1175/BAMS-D-11-00094.1.

Trenberth KE (1976). Spatial and temporal variations of the Southern Oscillation. Q. J. of the Roy. Meteor. Soc., 102(433):639-653. doi: $10.1002 /$ qj. 49710243310 .

Tudhope AW, et al. (2001). Variability in the El Niño-Southern Oscillation Through a Glacial-Interglacial Cycle. Science, 291(5508):1511-1517. doi: 10.1126/science.1057969.

Vincent DG (1994). The South Pacific Convergence Zone (SPCZ): A Review. Mon. Weather Rev., 122(9):1949-1970. doi:10.1175/15200493(1994)122<1949:TSPCZA > 2.0.CO;2.

Vincent EM, et al. (2011). Interannual variability of the South Pacific Convergence Zone and implications for tropical cyclone genesis. Clim. Dyn., 36(9-10):1881-1896. doi:10.1007/s00382-009-0716-3.

Widlansky MJ, Webster PJ, and Hoyos CD (2011). On the location and orientation of the South Pacific Convergence Zone. Clim. Dyn., 36(34):561-578. doi:10.1007/s00382-010-0871-6.

Widlansky MJ, et al. (2013). Changes in South Pacific rainfall bands in a warming climate. Nature Clim. Change, 3(4):417-423. doi: 10.1038/nclimate1726. 
504 Xie SP, et al. (2010). Global Warming Pattern Formation: Sea Sur505 face Temperature and Rainfall*. J. Clim., 23(4):966-986. doi: $506 \quad 10.1175 / 2009$ JCLI3329.1.

507 Zheng W, Braconnot P, Guilyardi E, Merkel U, and Yu Y (2008). ENSO at 508 6ka and 21ka from ocean-atmosphere coupled model simulations. Clim. 509 Dyn., 30(7-8):745-762. doi:10.1007/s00382-007-0320-3. 